\title{
Sistema penal inglés e imputación subjetiva $\left({ }^{*}()^{* *}\right)$
}

\section{English criminal system and mental states inference rules}

\author{
Armando Sánchez Málaga Carrillo( $\left.{ }^{* * *}\right)$ \\ Pontificia Universidad Católica del Perú
}

\begin{abstract}
Resumen: Si bien la discusión acerca de los elementos subjetivos del delito se encuentra aun en estado incipiente, el derecho penal inglés proporciona una perspectiva distinta de análisis, la cual consiste en anteponer el nivel aplicativo de la problemática del dolo -esto es, el nivel de determinación procesal del dolo- al nivel conceptual del mismo. La idea de que una teoría de los estados mentales sólo será satisfactoria si es que permite o hace viable su aplicación en el proceso penal puede constituir un aporte del desarrollo jurisprudencial inglés a la dogmática del derecho penal continental.
\end{abstract}

Palabras clave: Mens Rea - Intención Oblicua - Previsión - Temeridad Subjetiva - Responsabilidad Estricta - Presunción de Mens Rea - Inferencia de Estados Mentales

\begin{abstract}
Although the discussion about mens rea is still in an incipient state, English criminal law provides a different perspective of analysis, which establishes inference rules of the mental states before defining the conceptual level. The idea that a theory of mental states will only be satisfactory if it allows or makes viable its application in criminal proceedings can constitute a contribution of English jurisprudential development to the dogmatics of continental criminal law.
\end{abstract}

Key words: Mens Rea - Oblique Intention - Foresight - Subjective Recklessness - Strict Liability - Mens Rea Presumption - Inference

$\left(^{*}\right) \quad$ Nota del Editor: Este artículo fue recibido el 10 de abril y su publicación fue aprobada el 15 de junio del 2018.

${ }^{(* *}$ El presente artículo tiene como origen la estancia de investigación que su autor realizó en Reino Unido durante los años 2016 y 2017, y, específicamente, la ponencia que presentó como invitado en el seminario de Derecho penal y Derecho procesal penal de la Universidad de Barcelona realizado en diciembre de 2016 como parte del proyecto "Teoría del delito y proceso penal: ¿dos instrumentos conciliables?".

$\left.{ }^{(\star *}\right)$ Doctor en Derecho por la Universidad de Barcelona (España). Magíster en Criminología y Sociología jurídico penal por la Universidad de Barcelona (España). Magíster en Derecho Penal y Ciencias Penales por la Universidad de Barcelona y la Universidad Pompeu Fabra (España). Especialista en "Compliance" y "Financial Crime Prevention" por la International Compliance Association (Reino Unido). Abogado por la Pontificia Universidad Católica del Perú. Profesor del Departamento de Derecho de la Pontificia Universidad Católica del Perú. Socio del estudio Yon Ruesta, Sánchez Málaga \& Bassino Abogados. Consultor externo de la Organización Internacional del Trabajo. Correo electrónico: asanchezmalaga@yonruesta.com 
Sumario: 1. Introducción_2. Desarrollo_2.1.Sistema penal inglés_ 2.2. Criterios de determinación de estados mentales específicos_ 2.3. Supuestos de responsabilidad objetiva_2.4.Derecho procesal penal a partir del caso Woolmington v DPP (1935)_3. Conclusiones_4. Referencias bibliográficas_5. Jurisprudencia.

\section{Introducción}

En más de una ocasión, los jueces ingleses han resuelto casos de conductores de automóviles que, para evadir un control policial, continuaron su marcha generando peligro o incluso atropellando al agente de policía que les ordenaba detenerse. En un caso en el que el agente de policía resultó muerto (DPP vs. Smith $\left.{ }^{(1)}\right)$, la Cámara de los Lores estimó que el imputado era autor de un delito de homicidio intencional, mientras que en un supuesto similar en el que el agente policial había logrado evadir al automóvil y salvar su vida

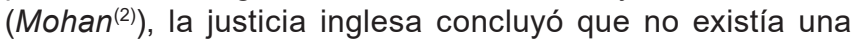
intención específica del conductor y que debía anularse la condena por tentativa de lesiones dolosas. La discusión en ambos casos no se centró en aspectos conceptuales del dolo, sino en cómo establecer un baremo que permitiera probar la intención. Si bien el tratamiento dogmático de los elementos subjetivos del delito muestra un estado incipiente, el derecho penal inglés proporciona una perspectiva distinta de análisis, la cual consiste en anteponer el nivel aplicativo del dolo (de su determinación procesal) al nivel conceptual del mismo. Se atiende así a la necesidad de que toda institución jurídica, además de legítima, sea viable y útil. Ello en la línea expuesta por Corcoy de que no tiene sentido exigir un elemento en el dolo que no pueda ser apreciado ${ }^{(3)}$.

El presente artículo brinda en cuatro apartados una visión panorámica de cómo las cortes inglesas han abordado la problemática de los estados mentales del delito. Se presentan las características generales del sistema penal inglés, los criterios jurisprudenciales de determinación de estados mentales específicos, los supuestos de responsabilidad objetiva y algunas características del derecho procesal inglés en materia de prueba de los elementos subjetivos del delito.

\section{Desarrollo}

\subsection{Sistema penal inglés}

El derecho penal ingles ${ }^{(4)}$ se caracteriza por la ausencia de un Código Penal y por la existencia de un sistema normativo complejo y confuso. Dichas carencias han generado que las cortes inglesas desarrollen un importante catálogo de principios y garantías procesales, así como que centren su atención en la problemática de la inferencia de los estados mentales más allá de su conceptualización. En materia de imputación subjetiva, se trata entonces de un sistema judicial que centra su atención en el nivel aplicativo antes que en el nivel conceptual(5).

Ormerod y Laird sostienen que el derecho penal inglés presenta conflictos con el principio de legalidad, toda vez que delitos graves, como el homicidio, derivan del derecho común (common law) y no de normas escritas (statutes) $^{(6)}$. Frente a ello, en las últimas décadas las cortes inglesas han resuelto que no deben crear nuevos delitos. En el

(1) DPP vs. Smith [1960] AC 290

(2) Mohan [1975] 2 All ER 193, [1975] 60 Cr App R 272

(3) Mirentxu Corcoy, El delito imprudente. Criterios de imputación del resultado, $2^{\mathrm{a}}$ ed. (Buenos Aires: B de F, 2008), 264. Ver también Patricia Laurenzo, Dolo y conocimiento (Valencia: Tirant lo Blanch, 1999), 19.

(4) Una visión comparativa en Weigend, "Subjective elements of criminal liability", en Markus Dubber, Tatjana Hörnle, The Oxford Handbook of Criminal Law (Oxford: Oxford University Press, 2014), 490 y siguientes

(5) Con relación al desarrollo de la dogmática del dolo en derecho penal occidental, que contrasta con la situación del sistema penal inglés, véase Ramón Ragués, El dolo y su prueba en el proceso penal (Barcelona: Bosch, 1999); Gabriel Pérez Barberá, El dolo eventual. Hacia el abandono de la idea de dolo como estado mental (Buenos Aires: Hammurabi, 2010); Armando Sánchez-Málaga, Una teoría para la determinación del dolo. Premisas teóricas e indicadores prácticos (Montevideo: B de F, 2018).

(6) David Ormerod, y Karl Laird, Smith and Hogan's Criminal Law, 14ª ed. (Oxford: Oxford University Press, 2015$), 17$. 


\section{Armando Sánchez Málaga Carrillo}

caso Jones et a/(7), la Cámara de los Lores (House of Lords) (8) estableció que las normas escritas son la única fuente de creación de nuevos delitos; y en el caso Goldstein and Rimmington ${ }^{(9)}$, dispuso que las cortes no tienen poder para abolir delitos ${ }^{(10)}$.

Gran parte del derecho penal inglés está recogido en miles de estatutos independientes, que son normas escritas que regulan sectores específicos y no se limitan a asuntos penales. En el caso Chambers se sostiene que el derecho estatutario es prácticamente inaccesible, sobre todo si se tiene en cuenta que la mayor parte de la legislación es de rango secundario y no se encuentra consolidada ${ }^{(11)}$. Frente a tal situación, se ha desarrollado el principio según el cual, si una disposición es ambigua, debe ser interpretada de la forma más favorable para el acusado. Del mismo modo, ha ganado influencia el derecho penal de la Unión Europea y, a partir de la promulgación de la ley de derechos humanos (Human Rights Act 1998), se obliga a las cortes a tener en cuenta la jurisprudencia de la Corte Europea de Derechos Humanos. En esa línea, la Convención Europea de Derechos Humanos establece las prohibiciones de criminalizar retroactivamente y de sancionar ofensas criminales vagas, así como el principio de presunción de inocencia ${ }^{(12)}$.

Si bien en Reino Unido no existe la estructura del Estado social y democrático de Derecho, conforme la expone en España Mir Puig ${ }^{(13)}$, y no se cuenta con un principio constitucional de culpabilidad, la jurisprudencia entiende que la atribución de los estados mentales al imputado está sometida a principios que limitan la potestad punitiva del Estado y protegen la libertad individual del ciudadano.
2.1.1. Principios generales de los elementos subjetivos del delito

La teoría del delito inglesa se construye a partir de la máxima latina actus non facit reum nisi mens sit rea, que significa que un acto en sí mismo no es culpable a no ser que se realice con una mente culpable ${ }^{(14)}$. El fundamento de este principio radica en que la responsabilidad penal debe ser atribuida solo a las personas que estuvieron suficientemente al tanto de lo que hacían y de las consecuencias de su actuar, esto es, que tuvieron la posibilidad de elegir su conducta y sus consecuencias ${ }^{(15)}$. A partir de ello, en la mayor parte de los delitos, la acusación debe probar dos elementos: (i) el elemento objetivo (actus reus), que consiste en una acción, una omisión o un estado de cosas $^{(16)}$, y (ii) el elemento subjetivo (mens rea), que consiste en un estado mental expresa o implícitamente requerido por la definición del delito imputado ${ }^{(17)}$. Frente a ello, el imputado podrá alegar defensas (defenses), que comprenden causas de justificación de la conducta y causas de exculpación del autor.

En DPP vs. Majewski, se define el elemento subjetivo como "el estado de ánimo estigmatizado como ilícito por el derecho penal que, cuando se combina con la conducta prohibida, constituye delito"(18). Como explica Padfield, el elemento subjetivo puede extenderse a algunos 0 a todos los

(7) Jones et al [2006] UKHL 16, citado por Ormerod, Laird, Smith and Hogan's, 18

(8) Hasta el año 2009, la Cámara de los Lores fue la corte de mayor jerarquía en Reino Unido, siendo reemplazada por la Corte Suprema (Supreme Court). En Ormerod, Laird, Smith and Hogan's, 45.

(9) Goldstein and Rimmington [2005] UKHL 63, citado por Ormerod, Laird, Smith and Hogan's, 18.

(10) Caso distinto es el de las defensas (como el error, la inimputabilidad, la coacción y el estado de necesidad), cuya fuente indiscutible de regulación sigue siendo el derecho común.

(11) Chambers [2008] EWCA Crim 2467, citado por Ormerod, Laird, Smith and Hogan's, 19.

(12) Ormerod, Laird, Smith and Hogan's, $14^{\mathrm{a}}$ ed., 2015, pp. 19-29.

(13) Santiago Mir Puig, Derecho penal, Parte General, $10^{\mathrm{a}}$ ed. (Barcelona: Reppertor, 2015), lección $4^{\mathrm{a}}$.

(14) Jacqueline Martin, Key Facts Key Cases. Criminal Law, (Routledge Taylor \& Francis Group, 2014$), 5$.

(15) Andrew Ashworth, Jeremy Horder, Principles of Criminal Law, $7^{\text {a }}$ ed. (Oxford: Oxford University Press, 2013 ), 155.

(16) Martin, Key Facts Key Cases. Criminal Law, Routledge Taylor \& Francis Group, 2014, p. 18.

(17) Richard Card, Card, Cross \& Jones Criminal Law, 21 a ed. (Oxford: Oxford University Press, 2012), 69.

(18) DPP vs. Majewski [1977] AC 443, citado por Padfield, Criminal Law, 8 a ed., Oxford University Press, 2012 , p. 43 (traducción libre del autor). 
elementos objetivos del delito. Puede ser el caso también que cada elemento objetivo de un delito requiera un estado mental distinto(19). Los estados mentales principales que trata la jurisprudencia inglesa son la intención (intention) y la temeridad (recklessness) ${ }^{(20)}$. También se valoran el conocimiento (knowledge) y la ceguera voluntaria (wilful blindness), los que se diferencian de la mera creencia (belief) y la sospecha (suspicion). Distinto es el caso de la negligencia (negligence), que no es propiamente un estado mental, sino más bien la conducta que cae por debajo del estándar objetivo que se espera de una persona razonable en determinadas circunstancias ${ }^{(21)}$. Según Ashworth y Horder, la distinción entre intención y temeridad, por un lado, y negligencia, por el otro, puede entenderse como la diferencia entre efectos previstos y efectos que fueron imprevistos solamente porque el agente no prestó la atención que pudo y debió haber prestado(22).

Oxman alude a los estadios preliminares de la evolución del concepto de mens rea en el derecho penal inglés, destacando los casos Regina contra Price (1875) y Regina contra Faulkner (1877), los cuales elevaron la culpabilidad a la categoría de principio fundamental ${ }^{(23)}$. A partir de ello, se han desarrollado principios que guían el tratamiento de los elementos subjetivos del delito:

a) El principio de correspondencia (the correspondence principle) dispone que a cada elemento objetivo del delito debe corresponderle un estado mental. Según Ormerod y Laird, este principio no tiene aplicación general(24), ya que no se tiene en cuenta al menos en tres casos:

- En el caso de los delitos de responsabilidad estricta u objetiva (offences of strict liability), que son aquellos en los que al menos un elemento objetivo del delito no se encuentra abarcado por un estado mental (25). Un ejemplo es el delito de violación de un menor de trece años, en el que se exige a la acusación probar que el autor realizó el acto sexual con intención, pero no se le exige probar ningún estado mental del autor respecto de la edad de la víctima. Otro ejemplo es el delito de lesiones, en el que se exige a la acusación probar que el autor realizó una conducta voluntaria con la intención o la temeridad de agredir a la víctima, pero no se exige probar ningún estado mental respecto del resultado de lesión.

- En el caso de los delitos constructivos (constructive crimes), en los que únicamente se exige la prueba del estado mental previsto para un delito menor. Un ejemplo es el homicidio intencional, en el que sólo se exige a la acusación probar que el autor actuó con la intención de causar un serio daño corporal, más no se exige probar la intención de matar.

- Finalmente, en el caso de los delitos de intención ulterior (crimes of ulterior intent), en los que el estado mental incluye la intención de producir una

(19) Padfield, Criminal Law, 43.

(20) La traducción del término recklessness es compleja. En este artículo, se opta por traducirlo como "temeridad", teniendo en cuenta que varios preceptos del Código penal español vigente equiparan la temeridad al dolo. No se comparte la propuesta de traducirlo como "desconsideración" o "indiferencia", en vista de la connotación altamente subjetiva de estos términos y su relación con el carácter del autor. Véase también definiciones en el Código Penal Modelo de Estados Unidos en Ramón Ragués, La ignorancia deliberada en Derecho penal (Barcelona: Atelier, 2008), 69 y siguientes.

(21) Ormerod, Laird, Smith and Hogan's, 161-163, quienes precisan que no se trata de un estándar absolutamente objetivo, ya que se incorpora al baremo el conocimiento especial del imputado. Ahora bien, si el imputado tiene un conocimiento o capacidad menores de previsión que una persona razonable, ello en principio no lo ayudará.

(22) Ashworth, Horder, Principles of Criminal Law, 182.

(23) Nicolás Oxman, Sistemas de imputación subjetiva en Derecho Penal. El modelo angloamericano (México: Tirant lo Blanch, 2016), 54 y siguientes

(24) Ormerod, Laird, Smith and Hogan's, 148-149.

(25) Ormerod, Laird, Smith and Hogan's, 114. 


\section{Armando Sánchez Málaga Carrillo}

consecuencia que va más allá de los elementos objetivos del delito. Un ejemplo es el delito de robo, en el que no sólo se exige a la acusación probar la intención de cometer el robo, sino también la intención de cometer otras ofensas (por ejemplo, agresiones) que no forman parte del tipo objetivo del delito de robo.

b) El principio de coincidencia dispone que el estado mental del imputado debe coincidir en el tiempo con la conducta objetiva que configura el delito ${ }^{(26)}$. La vigencia de este principio es parcial, ya que no opera en aquellos casos en los que se aplica la doctrina de la culpa previa (doctrine of prior fault), que se asemeja a la estructura del actio libera in causa del derecho penal continental y que establece que no debe permitirse que una persona tome ventaja de una defensa si la condición que la habilita fue generada por su culpa(27).

c) El principio de transferencia (transferred mens rea) establece que el imputado es culpable si intentó cometer un delito similar pero contra una víctima distinta de la que finalmente sufrió las consecuencias del acto ${ }^{(28)}$. En Latimer, el imputado tuvo una pelea con otro sujeto, a quien le lanzó su cinturón con la finalidad de hacerle daño. Sin embargo, el cinturón apenas rozó a su contendiente y, más bien, hirió severamente a una mujer que se encontraba en el lugar y que no había participado de la pelea. El juez aplicó el principio de transferencia y explicó: "Un hombre que tiene una intención ilícita y maliciosa contra otro, y al intentar llevarla a cabo, lesiona a una tercera persona, es culpable de lo que la ley considera malicia contra la persona herida, porque el ofensor está realizando un acto ilícito y tiene lo que los jueces llaman malicia general"(29).

d) Un cuarto principio dicta que la ignorancia del derecho no puede constituir una defensa que exima de responsabilidad penal. Ormerod y Laird explican que este principio no plantea dificultad frente a los crímenes más serios, ya que todo el mundo sabe que matar, robar o violar son conductas contrarias a la ley; sin embargo, frente a los delitos menos graves, es posible que el sujeto, sin negligencia, sea ignorante de que un acto particular constituye delito. Distinto es el caso del error de derecho, que permite eximir de responsabilidad penal en caso implique que el imputado actuó sin intención o sin temeridad respecto de algún elemento objetivo del delito ${ }^{(30)}$.

e) Finalmente, se hace referencia a la existencia de un principio de confianza en el ámbito subjetivo, según el cual una persona es responsable "por la desconsideración de los riesgos que debía o le era exigible saber en la situación específica en la que tuvo lugar el hecho"(31).

2.1.2. Método de aproximación jurisprudencial a los elementos subjetivos del delito

El sistema penal inglés presta especial atención al desarrollo de criterios para determinar los estados mentales del autor en el caso concreto. En los últimos años, la evolución de la jurisprudencia inglesa se ha mostrado en tres direcciones. En primer lugar, las cortes inglesas han abandonado la antigua presunción de derecho de que una persona prevé y tiene la intención de realizar "las consecuencias naturales" de sus actos ${ }^{(32)}$. Por el contrario, en la actualidad las cortes inglesas se esfuerzan por probar cuál fue el estado mental del imputado al momento de realizar el acto.

(26) Ormerod, Laird, Smith and Hogan's, 153.

(27) Ashworth, Horder, Principles of Criminal Law, 159.

(28) Martin, Key Facts Key Cases, 37.

(29) Latimer [1886] 17 QBD 359, citado por Martin, Key Facts Key Cases, 45-46 (traducción libre del autor).

(30) Ormerod, Laird, Smith and Hogan's, 157-158.

(31) Oxman, Sistemas de imputación subjetiva en Derecho Penal, 43, citando a Robinson, Structure, 148.

(32) Ormerod, Laird, Smith and Hogan's, 159. 
En segundo lugar, las cortes inglesas muestran una tendencia a apartarse de criterios o valoraciones morales a la hora de determinar el estado mental imputado ${ }^{(33)}$. Card señala que la determinación del estado mental del imputado es ajena a la noción de mente malvada, a la existencia de una falta moral y al conocimiento de la ilicitud de la conducta ${ }^{(34)}$. Sin embargo, ello no siempre fue así. Por ejemplo, en el caso Steane (1947), un ciudadano británico difundió propaganda a favor de Alemania durante la Segunda Guerra Mundial, arguyendo que lo hacía para salvar a su esposa e hijo que aún se encontraban en territorio alemán. La Corte de Apelación Criminal (Court of Criminal Appeal) estableció que el ciudadano británico había actuado "sin intención criminal", ya que estaba guiado por el "deseo" de salvar a su familia. Esta decisión es hoy cuestionada y la doctrina inglesa entiende que el caso debió ser tratado a través de la excusa de la coacción ${ }^{(35)}$.

En tercer lugar, existe una controversia acerca del método de aproximación a los estados mentales, la cual se asemeja a la discusión mantenida en el derecho penal occidental entre los enfoques psicológicos y normativos del dolo ${ }^{(36)}$, que en Reino Unido se traduce en el conflicto entre el principio de autonomía individual y el principio de bienestar ${ }^{(37)}$. Al respecto, Ormerod y Laird ${ }^{(38)}$ destacan dos planteamientos muy diferenciados acerca de lo que debe ser acreditado en juicio. Por un lado, el planteamiento de los subjetivistas ${ }^{(39)}$, quienes proponen que, al menos en los delitos más graves, el elemento mental requiere la prueba de que el acusado tuvo conciencia personal de sus acciones y fue consciente de las circunstancias relevantes y de las consecuencias que forman parte de los elementos objetivos del delito. Por otro lado, el planteamiento de los objetivistas, para quienes es suficiente probar que una persona razonable hubiera sido consciente de las circunstancias y consecuencias relevantes que forman parte del delito, independientemente de si el acusado fue consciente de las mismas. Card sostiene que, en tiempos modernos, las cortes inglesas han mostrado una preferencia por juzgar al imputado sobre la base de lo que intento o conoció, antes que sobre la base de lo que una persona razonable hubiera realizado ${ }^{(40)}$. Sin embargo, Ormerod y Laird destacan que existen diversas posturas intermedias. Así, mientras que los tribunales se acercan más al planteamiento de los subjetivistas, el Parlamento inglés ha mostrado una tendencia por crear cada vez más delitos con elementos de responsabilidad objetiva o estandarizada.

Más allá del planteamiento que se asuma, es mayoritario el reconocimiento de que los jueces penales no tienen a su disposición una prueba directa del estado mental del imputado; por lo que el método para dar por acreditados los estados mentales principales (intención, temeridad y conocimiento) es la inferencia a partir de las instrucciones que el juez proporcione al jurado. Según explica Oxman, este juicio parte de la imposibilidad de saber lo que el imputado pensaba, por lo que debe acreditarse la acción realizada y el contexto en el que tuvo lugar (incluyendo la conducta previa y la ejecución) a efectos de inferir el estado mental con el que actuó.

(33) Acerca de las razones por las que los motivos se excluyen de la cuestión de la responsabilidad penal y aquellos supuestos en los que un buen motivo podría ser valorado por las cortes inglesas, ver De Than, Heaton, Criminal Law, $4^{\mathrm{a}}$ ed., (Oxford: Oxford University Press, 2013), 62-65.

(34) Card, Card, Cross \& Jones Criminal Law, 69.

(35) Steane [1947] KB 997, [1947] 1 All ER 813, citado por Padfield, Criminal Law, 44.

(36) Acerca de la controversia en derecho penal continental, véase HRUschKA, "Sobre la difícil prueba del dolo", en Hruschka, Imputación y Derecho penal. Estudios sobre la teoría de la imputación, (B de F, 2009), 181 y siguientes.

(37) Ashworth, Horder, Principles of Criminal Law, 185.

(38) Ormerod, Laird, Smith and Hogan's, 114-115.

(39) Al respecto, Ashworth, Horder, Principles of Criminal Law, 156, sostienen que los subjetivistas otorgan gran valor no sólo al principio de mens rea, sino también al principio de correspondencia, el cual entra en disputa con las propuestas de responsabilidad constructiva (constructive liability).

(40) Card, Card, Cross \& Jones Criminal Law, 69. 


\section{Armando Sánchez Málaga Carrillo}

La presunción de inocencia se rompe cuando el jurado es persuadido de que un estado mental "aparece" más allá de toda duda razonable, en relación con la forma en que se han tenido por probados los hechos ${ }^{(41)}$.

\subsection{Criterios de determinación de estados mentales específicos}

2.2.1. Intención (intention)

La intención es el elemento subjetivo de mayor intensidad y suele ser exigido en los delitos más graves. Se trata de un concepto más amplio que el de premeditación, ya que incluye las conductas espontáneas ${ }^{(42)}$. La intención no ha sido definida por el Parlamento, sino por las cortes inglesas. El término "intención" no se limita a aquellos casos en los que el imputado tiene un objetivo o resultado en la mente e intenta conseguirlo (direct intent), sino que también comprende los supuestos de intención oblicua (oblique intent), que son aquellos casos en los que el imputado tiene un propósito en mente pero, para lograrlo, causa otras consecuencias no necesariamente deseadas ${ }^{(43)}$. Si bien es difícil hacer una equivalencia con el derecho penal continental, puede afirmarse que la intención comprende por lo menos los supuestos de dolo directo y dolo de segundo grado.

¿Cómo se determina la intención en el caso concreto? Con relación a la intención directa, Duff propuso un examen según el cual existiría intención en aquellos casos en los que, si el resultado no se hubiera producido, el imputado habría considerado su acción como una falla. Sin embargo, este examen fracasa cuando el resultado es solamente un medio para lograr el verdadero objetivo del imputado(4) ejemplo, heredar la fortuna de la víctima de homicidio). Con relación a la intención oblicua, Ashworth y Horder afirman que no se trata de un concepto o forma de intención, sino de un medio de inferencia de la intención ${ }^{(45)}$, es decir, de un instrumento de aplicación del concepto. A continuación, se presenta una selección de casos de homicidio que muestra cómo han evolucionado los criterios de las cortes inglesas para dar contenido al proceso de inferencia de la intención:

\section{a. Caso DPP vs. Smith $(1961)^{(46)}$ :}

Hecho: Mientras que el imputado conducía su automóvil en posesión de objetos robados, se cruzó con un control policial que le ordenó detenerse. Sin embargo, el imputado aceleró su marcha, atropellando al policía que le hacía señas para que se detuviera. El policía resultó muerto.

Resolución: La Cámara de los Lores estimó que el imputado era autor de un delito de homicidio intencional.

Criterio aportado: La Cámara de los Lores estableció un baremo objetivo, con dos indicadores. Existía homicidio intencional cuando la muerte de la víctima era previsible y cuando una persona razonable situada en la posición del autor hubiera previsto el riesgo de muerte. La resolución de este caso generó una recomendación de la Comisión de Reforma ${ }^{(47)}$, que dio lugar a la redacción del artículo $8^{\circ}$ de la Ley de Justicia Criminal de 1967, cuyo objeto era restringir el baremo objetivo y establecer la obligación de valorar las circunstancias del caso concreto: "Un tribunal o jurado, al determinar si una persona ha cometido un delito: (A) no estará obligado a inferir que el imputado pretendió o previó un resultado de su acción sólo por ser la consecuencia natural y probable de dicha acción; y (B) decidirá si el imputado actuó con intención o previsión de

(41) Oxman, Sistemas de imputación subjetiva en Derecho Penal, 66-67.

(42) Ormerod, Laird, Smith and Hogan's, 116-117.

(43) Martin, Key Facts Key Cases, 33.

(44) Cristina McAlhone, Natalie Wortley, Criminal Law. The Fundamentals, $3^{a}$ ed., (Sweet and Maxwell, 2013, 53-54.

(45) Ashworth, Horder, Principles of Criminal Law, 173.

(46) DPP vs. Smith [1960] AC 290

(47) Informe de 12.12.1966. Ver Oxman, Sistemas de imputación subjetiva en Derecho Penal, 104-105. 
dicho resultado en base a todas las pruebas, efectuando una inferencia a partir de la evidencia tal como aparezca de las circunstancias del caso concreto"(48).

\section{b. Caso Hyam vs. DPP (1975) ${ }^{(49)}$ :}

Hecho: La imputada, con el supuesto fin de amendrentar a su ex pareja, quemó el buzón de la puerta principal de su casa, luego de constatar que su ex pareja no se encontraba en el lugar. Sin embargo, producto del incendio, murieron dos menores de edad que se encontraban al interior de la casa.

Resolución: La Cámara de los Lores confirmó la condena por homicidio intencional y ratificó que la intención no se limita a casos de intención directa, sino que comprende los de intención oblicua.

Criterio aportado: La Cámara de los Lores dispuso que las cortes podían establecer que un resultado había sido intencional, aun cuando no hubiera sido el propósito del autor causarlo, si es que el resultado era una consecuencia prácticamente segura de su conducta y el autor tenía conocimiento de ello(50). Según anota Padfield, la amplia concepción de la intención presentada por esta sentencia generó una década de incertidumbre en la judicatura inglesa, siendo el caso Mohan quizás el intento más claro de la Corte de Apelaciones por delimitar el ámbito de la intención ${ }^{(51)}$.

\section{c. Caso Mohan (1976)(52):}

Hecho: Con el fin de escapar, el imputado condujo su automóvil en dirección a donde se encontraba un oficial de policía. El oficial logró evadir al automóvil y no fue atropellado.

Resolución: La Corte de Apelaciones (Court of Appeal Criminal Division) anuló la condena por tentativa del delito de lesiones en agravio de un oficial de policía producto de la conducción temeraria, al no haberse acreditado la existencia de una intención específica.

Criterios aportados: La Corte sostuvo que no era suficiente para atribuir un delito intencional que el imputado hubiera previsto las consecuencias de su actuar. Asimismo, efectuó una clara delimitación entre intención y mero deseo, definiendo la intención como "una decisión de llevar a cabo, en la medida de las posibilidades del acusado, la consecuencia prohibida, sin que importe si el acusado deseaba la consecuencia de su acto o no"(53).

\section{d. Caso Moloney (1985)(54):}

Hecho: El imputado disparó y mató a su padrastro, mientras ambos bebían y participaban de un juego acerca de quién era más rápido utilizando una escopeta.

Resolución: La Cámara de los Lores anuló la condena por homicidio intencional y tipificó el caso como uno de homicidio imprudente (manslaughter).

Criterios aportados: La Cámara de los Lores estableció que la previsión de las consecuencias no era asimilable a la intención, sino que solo podía ser considerada como una evidencia de la intención ${ }^{(55)}$. En la sentencia, Lord Bridge afirmó que estaba firmemente convencido de que la previsión de las consecuencias, como elemento que

(48) Criminal Justice Act. http://www.legislation.gov.uk/ukpga/1967/80 (consultada el 10 de diciembre de 2016) (traducción libre del autor).

(49) Hyam vs. DPP [1975] AC 55.

(50) Ormerod, Laird, Smith and Hogan's, 117.

(51) Padfield, Criminal Law, 46.

(52) Mohan [1975] 2 All ER 193, [1975] 60 Cr App R 272.

(53) Martin, Key Facts Key Cases, 39 (traducción libre del autor).

(54) Moloney [1985] 1 All ER 1025, [1985] 81 Cr App R 93. Mayor detalle en Martin, Key Facts Key Cases, 39.

(55) En ese sentido, Martin, Key Facts Key Cases, 34. Véase también Card, Card, Cross \& Jones Criminal Law, 72. 


\section{Armando Sánchez Málaga Carrillo}

tiene que ver con la cuestión de la intención en el asesinato o cualquier otro delito de intención específica, no pertenecía al derecho sustantivo, sino al derecho de la prueba ${ }^{(56)}$. Por otro lado, la sentencia definió aquello que se consideraba "previsión de las consecuencias". Al respecto, Lord Bridge sostuvo que, para afirmar la intención, era necesaria una "certeza moral", una probabilidad que fuera poco menos que abrumadora de que la acción del imputado conduciría al resultado a menos que algo inesperado surjiese para evitarlo(57). Se planteó el test de la "consecuencia natural", que establecía que podía afirmarse que el imputado había actuado con intención cuando la muerte era una consecuencia natural de sus actos y él mismo había previsto la muerte como consecuencia natural de sus actos. Se estableció así un baremo subjetivo que deshacía la confusión entre probabilidad e intención del caso Hyam vs. DPP. Sin embargo, como menciona Padfield, el caso dejó abierta la pregunta de cuándo la muerte podía ser considerada la consecuencia natural de un determinado acto(58).

\section{e. Caso Hancock and Shankland (1986)(59):}

Hecho: Los imputados, con la supuesta intención de evitar que sus compañeros de trabajo concurriesen a trabajar y rompiesen la huelga que mantenían, empujaron dos bloques de hormigón desde un puente hacia la carretera que conducía a su centro de labores. Al caer los bloques de hormigón, golpearon el taxi en el que se desplazaba uno de sus compañeros. El taxista murió.

Resolución: La Cámara de los Lores confirmó la sentencia de la Corte de Apelaciones que había sustituido la calificación de homicidio intencional por una de homicidio no intencional, al entender que no era suficiente la previsión del resultado para imputar la intención, sino que debía acreditarse una probabilidad rayana en la certeza ("certeza moral").
Criterio aportado: La Cámara de los Lores sostuvo que la alta probabilidad de que ocurriera el resultado era algo que debía tenerse en cuenta al decidir si se podía inferir la intención, aunque no tenía por qué ser un criterio determinante. En esa línea, Lord Scarman sugirió que el test de la "consecuencia natural" del caso Moloney era demasiado amplio ${ }^{(60)}$, debiendo ser reemplazado por la siguiente consideración: "cuanto más alta es la probabilidad de una consecuencia es más probable que esta haya sido prevista y, si la consecuencia fue prevista, es más alta la probabilidad de que la consecuencia haya sido querida (intencional)"(61).

\section{f. Caso Nedrick (1986) ${ }^{(62):}$}

Hecho: Con la supuesta finalidad de asustar al dueño de casa, el imputado derramó parafina en el buzón de correos situado frente al predio y encendió fuego. Sin embargo, el resultado fue la muerte del niño que se encontraba al interior del inmueble producto de la propagación del fuego.

Resolución: La Corte de Apelaciones sustituyó la calificación de homicidio intencional por una de homicidio no intencional.

Criterio aportado: La Corte reiteró que la previsibilidad de las consecuencias de un hecho no pertenece al aspecto sustantivo del derecho penal, sino que es "parte de la cuestión procesal derivada de la valoración de la evidencia"(63). Asimismo, enfatizó que

(56) En Martin, Key Facts Key Cases, 39

(57) Ormerod, Laird, Smith and Hogan's, 124.

(58) Padfield, Criminal Law, 47.

(59) Hancock and Shankland [1986] 1 All ER 641, [1986] 82 Cr App R 264. Mayor detalle en Martin, Key Facts Key Cases, 35.

(60) Padfield, Criminal Law, 48.

(61) Card, Card, Cross \& Jones Criminal Law, 73.

(62) Nedrick [1986] 3 All ER 1, [1986] 83 Cr App R 267. Mayor detalle en Martin, Key Facts Key Cases, 35.

(63) Oxman, Sistemas de imputación subjetiva en Derecho Penal, 110-111. 
la previsión (entendida como "virtual certeza") del resultado no era más que una prueba de la cual se podía inferir la intención ${ }^{(64)}$. Sugirió entonces que, a efectos de evaluar la existencia de intención en el caso concreto, los jurados se preguntaran cuán probable era la consecuencia que resultó del acto voluntario del imputado y si el imputado previó dicha consecuencia ${ }^{(65)}$.

\section{g. Caso Woolin (1998)(66):}

Hecho: El imputado, en un momento de ira, lanzó a su hijo de tres meses de edad a una superficie dura, causándole la muerte.

Resolución: La Cámara de los Lores revocó la condena por homicidio intencional y la reemplazó por una condena por homicidio no intencional.

Criterios aportados: La Cámara de los Lores aprobó las directivas del caso Nedrick, aunque estableció que era preferible utilizar la expresión "encontrar" antes que "inferir", así como desaprobó el uso de las dos interrogantes formuladas para el jurado. Estableció entonces la siguiente directiva: "Los miembros del jurado deben ser dirigidos en el sentido de que no deben 'encontrar' un supuesto de intención a menos que se sientan seguros de que la muerte o el daño físico grave, salvo una intervención imprevista, eran el resultado cierto ("virtual certeza") de la acción realizada por el imputado y que el imputado apreció que tal era el caso"(67). Por otro lado, Lord Steyn sostuvo en la sentencia que "un resultado previsto como virtualmente cierto es el resultado deseado". Según Ormerod y Laird, esta última afirmación ha merecido dos lecturas distintas. Por un lado, una lectura literal, según la cual, una vez que la corte o el jurado determinan que el acusado ha tenido tal previsión, debe concluir que existió una conducta intencional. Por otro lado, una interpretación restrictiva, según la cual, cuando la corte o el jurado determinan que el acusado ha previsto como virtualmente cierto el resultado, pueden estimar que se trata de una conducta intencional ("encontrarla"), aunque no están obligados a concluir que existió intención(68). La primera alternativa privilegia una mayor certeza y seguridad jurídica, mientras que la segunda apunta a una mayor justicia, al valorar otras circunstancias del caso concreto. Otro aporte del caso Woollin es la idea de que la intención no tiene necesariamente el mismo significado en todos los contextos del derecho penal ${ }^{(69)}$. No han faltado las críticas contra la resolución de este caso, sobre todo aquellas que apuntan a que la previsión y la intención son estados mentales, no pudiendo inferirse una de la existencia de la otra(70).

Cercano en el tiempo es el caso MD (2004)(71), en el que la Corte de Apelaciones -en una suerte de compilado de casos anterioressostuvo que la intención oblicua cubre aquellos casos en los que el imputado realiza un acto sin el propósito de matar, pero en circunstancias en las que la muerte tiene una virtual certeza de acontecer como resultado de su acción y el imputado lo ha apreciado asi(72).

Siguiendo a Mcalhone y Wortley, puede concluirse que la intención oblicua plantea la relación entre dos instituciones: la intención y la previsibilidad. Al respecto, existen dos visiones. Por un lado, el punto de vista de la

(64) Ormerod, Laird, Smith and Hogan's, 119.

(65) Martin, Key Facts Key Cases, 35.

(66) Supra nota 65.

(67) Woollin [1998] UKHL 28, [1999] 1 Cr App R 8. Mayor detalle en Martin, Key Facts Key Cases, 41.

(68) Ormerod, Laird, Smith and Hogan's, 1119-120. Un mayor desarrollo de ambas lecturas en Card, Card, Cross \& Jones Criminal Law, 76 y siguientes.

(69) Ormerod, Laird, Smith and Hogan's, 125.

(70) Padfield, Criminal Law, 50.

(71) MD [2004] EWCA Crim 1391.

(72) Ormerod, Laird, Smith and Hogan's, 118. 


\section{Armando Sánchez Málaga Carrillo}

identidad, que asimila la previsión de una consecuencia a la existencia de intención. Por otro lado, el punto de vista de la inferencia, para el que la previsión de una consecuencia es una evidencia más de la cual el jurado puede -pero no debe- inferir la existencia de intención ${ }^{(73)}$. Este segundo punto de vista parece ser el que ha primado en la evolución jurisprudencial( ${ }^{(74)}$. Vinculada a esta discusión se encuentra la del grado de previsión que las cortes inglesas han fijado recientemente como un grado de "virtual certeza" (virtual certainty) ${ }^{(75)}$, certeza que no es exigida cuando el propósito es producir la consecuencia prohibida (intención directa) ${ }^{(76)}$.

Más allá de ello, los jueces ingleses dejan puntos sin resolver. Para Mcalhone y Wortley, no están claros los criterios para determinar en qué circunstancias puede encontrarse la intención cuando el imputado previó con un grado de certeza virtual la consecuencia de su hecho; ni si la intención oblicua debe aplicarse para todos los delitos que implican intención o sólo para el homicidio; y cuál es la relevancia de los buenos motivos del imputado en un caso de intención oblicua( ${ }^{(77)}$.

\subsubsection{Temeridad (recklessness)}

Un segundo estado mental considerado por la jurisprudencia inglesa es la temeridad, en la que el imputado decide llevar a cabo riesgos injustificables que pueden dañar a terceros. Según Ormerod y Laird, no se trata de cualquier toma de riesgo. Si bien no es posible indicar de forma general qué nivel de riesgo de la probabilidad de ocurrencia del daño se requiere para configurar un caso de temeridad, sí puede afirmarse que, si la actividad no tiene utilidad social, la mínima posibilidad de daño debería ser suficiente para concluir que existe temeridad, mientras que si el acto tiene un alto grado de utilidad social, solo un muy alto grado de probabilidad de grave daño que supere a la utilidad social permitiría la condena ${ }^{(78)}$. En este caso, resulta aún más difícil establecer una equivalencia con el derecho penal continental, ya que existe una versión subjetiva de la temeridad que se acerca a la noción de dolo eventual(79), pero también una versión objetiva que sería difícilmente compatible con la noción de dolo del derecho penal continental.

De acuerdo a lo concepción subjetiva de temeridad (advertent recklessness), para atribuir este estado mental, debe probarse que el imputado fue consciente de la existencia de un riesgo de producción del resultado prohibido o de alguna circunstancia del delito. Este criterio fue establecido a partir del caso Cunningham (1957)(80), en el que el imputado rompió un medidor de gas de la bodega de una casa ocupada a fin de robar el dinero que se encontraba en su interior, dejando salir el gas, el cual se filtró en una vivienda vecina, siendo inhalado por la víctima, cuya vida se puso en peligro. Para la Corte de Apelación Criminal, el acusado no podía ser culpable del delito de administración maliciosa de una sustancia tóxica salvo que hubiera sido consciente, cuando rompió el medidor de gas o cuando dejó la tubería con el gas filtrándose, que este podría ser inhalado por una persona. Para ser responsable, el acusado tendría que haber reconocido la existencia del riesgo y haberlo tomado deliberadamente ${ }^{(81)}$. A mayor detalle,

(73) Mcalhone, Wortley, Criminal Law, 56.

(74) Existe actualmente un proyecto de Código Penal del Reino Unido, que define la intención así: "una persona actúa intencionalmente con relación a un resultado cuando actúa con el fin de lograrlo o siendo consciente de que ocurrirá en el curso ordinario de los acontecimientos" (traducción libre del autor). Véase más en Ormerod, Laird, Smith and Hogan's, 126.

(75) Mcalhone, Wortley, Criminal Law, 56.

(76) De Than, Heaton, Criminal Law, 61.

(77) Mcalhone, Wortley, Criminal Law, 61.

(78) Ormerod, Laird, Smith and Hogan's, 129 y 132.

(79) Al respecto, ver Chiesa, "Comparative Criminal Law", en Hörnle, The Oxford Handbook of Criminal Law, 1089 y siguientes.

(80) Cunningham [1957] 2 All ER 412, [1957] 41 Cr App R 155.

(81) Ormerod, Laird, Smith and Hogan's, 130. 


\section{Sistema penal inglés e imputación subjetiva English criminal system and mental states inference rules}

Ashworth y Horder sostienen que la temeridad subjetiva implica tres elementos: previsión actual del riesgo, previsión de cualquier grado de riesgo y que resulte injustificado o irracional tomar dicho riesgo en las circunstancias del caso ${ }^{(82)}$.

Entre 1982 y 2003 se reemplazó el test subjetivo de temeridad por una concepción objetiva (objective recklessness), según la cual era suficiente para condenar al imputado acreditar que una persona razonable hubiera visto el riesgo aun cuando el acusado no. En el caso Metropolitan Police Comissioner vs. Caldwell (1982)(83), el imputado prendió fuego a la habitación de un hotel mientras estaba ebrio. Se le imputó entonces un delito de incendio provocado con intención o temeridad de poner en peligro la vida de terceros. La Cámara de los Lores confirmó la condena y estableció que una persona actúa con temeridad cuando realiza un acto que crea un riesgo evidente $\mathrm{y}$, al hacerlo, no piensa en la posibilidad de que hubiera tal riesgo o, habiendo reconocido que había algún riesgo involucrado, igual decide tomarlo( ${ }^{(84)}$. Se trató de un criterio que no sólo se pretendía usar en casos de daños, sino que se extendió a algún caso de causación de muerte por conducción temeraria, como fue el caso Lawrence ${ }^{(85)}$, en el que la Cámara de los Lores confirmó la revocación de la condena por causación de muerte por conducción temeraria impuesta a un sujeto que había conducido una motocicleta a $80 \mathrm{mph}$ en un vía urbana transitada, precisando que el test objetivo de temeridad debía exigir que el riesgo fuera "obvio y serio"(86).

Contra el planteamiento de la temeridad objetiva, se han formularon diversos cuestionamientos. Se le acusó de considerar menos culpable al individuo que había reflexionado sobre su conducta y decidido que no existía riesgo que a aquel que ni siquiera había reflexionado acerca de la peligrosidad de su conducta. Asimismo, se cuestionó que implicaba la aplicación de un test en perjuicio de gente joven, sin experiencia o con una capacidad disminuida para percibir el riesgo ${ }^{(87)}$.

Con el caso G (2003), la justicia inglesa rechazó el test objetivo de temeridad y retomó los criterios del caso Cunningham ${ }^{(88)}$. En aquel caso, dos menores de once y doce años de edad fueron de campamento $y$, durante la noche, prendieron fuego a unos periódicos y los arrojaron encendidos a una papelera, marchándose sin apagar el fuego. El incendio se extendió a una tienda cercana causando daños valorizados en un millón de libras ${ }^{(89)}$. La Cámara de los Lores anuló las condenas por delito de incendio provocado y eliminó el precedente de Caldwell que tildó de injusto y afirmó que "se podía confiar en que los jurados aplicarán la prueba de Cunningham sin aceptar ciegamente la afirmación de un acusado de que nunca pensó en un cierto riesgo cuando todas las circunstancias y probabilidades de lo que hizo y dijo en ese momento demuestran que debió haberlo hecho"(90).

Retomar el test subjetivo de temeridad permite diferenciar adecuadamente la temeridad de

(82) Ashworth, Horder, Principles of Criminal Law, 176-177. Véase también De Than, Heaton, Criminal Law, 82, quienes asimilan la indiferencia a la temeridad subjetiva.

(83) Caldwell vs. MPC [1982] AC 341, [1981] All ER 961

(84) Martin, Key Facts Key Cases, 36.

(85) Al respecto, ver Padfield, Criminal Law, 55.

(86) Mcalhone, Wortley, Criminal Law, $3^{\mathrm{a}}$ ed., 2013, p. 69. Ver más en De Than, Heaton, Criminal Law, 70-71, quienes precisan que debe tratarse de un riesgo obvio para una persona prudente y que la seriedad está referida tanto a la probabilidad del riesgo como a la gravedad del daño que podría producirse si el riesgo se materializa.

(87) Ormerod, Laird, Smith and Hogan's, 134. En la misma línea, Ashworth, Horder, Principles of Criminal Law, 180.

(88) Un análisis de los motivos por los que la Cámara de los Lores rechazó el caso Caldwell en De Than, Heaton, Criminal Law, 73.

(89) G [2003] UKHL 50, [2004] 1 AC 1034, [2003] 4 All ER 765. Ver detalle en Ormerod, Laird, Smith and Hogan's, 135.

(90) Ormerod, Laird, Smith and Hogan's, 137 (traducción libre del autor). 


\section{Armando Sánchez Málaga Carrillo}

la mera negligencia. Al respecto, Ormerod y Laird sostienen que, si el imputado es consciente del riesgo y decide tomarlo, actúa con temeridad, mientras que, si es inconsciente del riesgo pero tenía el deber de ser consciente del mismo, actúa con negligencia ${ }^{(91)}$. La negligencia implica entonces que el imputado incumpla el estándar de una persona razonable ${ }^{(92)}$. No se trata de un estado mental, sino de un criterio absolutamente objetivo.

¿Cómo diferenciar los casos de intención (sobre todo los de intención oblicua) de los supuestos de temeridad subjetiva? Si bien es cierto que en un buen número de delitos es indistinto que el elemento subjetivo sea intención o temeridad, también lo es que existen delitos que sólo admiten la comisión intencional. Según De Than y Heaton, tanto en la intención como en la temeridad subjetiva, el imputado es consciente de que el acto o consecuencia prohibidos pueden ocurrir, pero en la intención existe el factor agravante de que el imputado tiene el propósito de realizar el acto prohibido o causar la consecuencia prohibida. Dicho criterio no resulta suficiente para realizar una clara distinción, más aún si se tiene en cuenta que las cortes inglesas tienden a ampliar el ámbito de la intención, confundiendo los casos de intención oblicua con los supuestos de temeridad subjetiva ${ }^{(93)}$.

2.2.3. Conocimiento (knowledge) y otros elementos mentales La intención y la temeridad son los estados mentales que suele exigirse que tengan un vínculo de correspondencia con los elementos objetivos del delito (la conducta prohibida o sus consecuencias). Sin embargo, existen otros estados mentales como el conocimiento que las normas y cortes inglesas suelen exigir que mantengan un vínculo de correspondencia con las circunstancias del delito. Ormerod y Laird definen el conocimiento como un estado mental que, a diferencia de la intención que suele ser descriptiva de los estados de ánimo en cuanto a las consecuencias, se suele utilizar en relación con las circunstancias presentes del delito ${ }^{(94)}$. De Than y Heaton sostienen que, con relación a las circunstancias, el conocimiento tiende a reemplazar a la intención ${ }^{(95)}$. Se trata de un concepto de conocimiento como "creencia verdadera" que debe ser diferenciado de la mera creencia (belief). En el caso Hall, se precisa que la creencia, a diferencia del conocimiento, es aquel estado mental en el que el imputado no conoce con seguridad que la circunstancia existe, pero no puede llegar a otra conclusión razonable a la luz de todas las circunstancias ${ }^{(96)}$.

Martin explica que el conocimiento, además de abarcar los casos de conocimiento actual de un hecho particular y estar virtualmente seguro de que un hecho particular es cierto, comprende los supuestos en los que el imputado ha sido voluntariamente ciego frente a la verdad ${ }^{(97)}$. Al respecto, Card sostiene que, "desde el punto de vista de la aplicación del derecho penal, es positivo que el conocimiento incluya el caso en el que el imputado está virtualmente seguro sobre una circunstancia o está intencionalmente ciego frente a la misma"(98). Durante siglos, las cortes inglesas han interpretado que el conocimiento incluye los casos de ceguera voluntaria (wilful blindness) ${ }^{(99)}$. Ormerod y Laird recuerdan que en el caso Roper vs. Taylor Garages (Exeter), se distinguen tres grados de conocimiento, entre los que se

(91) Ormerod, Laird, Smith and Hogan's, 141.

(92) Martin, Key Facts Key Cases, 37.

(93) De Than, Heaton, Criminal Law, 53. Al respecto ver Hyam vs. DPP [1975] AC 55.

(94) Ormerod, Laird, Smith and Hogan's, 142.

(95) De Than, Heaton, Criminal Law, 78.

(96) Hall [1985] 81 Cr App R 260 at 264, [1985 Crim LR 377, citado por Padfield, Criminal Law, 53.

(97) Martin, Key Facts Key Cases, 37.

(98) Card, Card, Cross \& Jones Criminal Law, 90 (traducción libre del autor).

(99) Con relación a la discusión en derecho penal occidental acerca de la plausibilidad de imputar como dolosos los casos de ceguera voluntaria, ver los aportes de Ragués i Vallès, Puppo, Greco, Manrique, Feijoo Sánchez y Valenzuela en Bouvier (dir.), Discusiones XIII. Ignorancia deliberada y Derecho penal, EdiUNS, 2013. 
encuentra la ceguera voluntaria: (i) el conocimiento actual (que significa una creencia verdadera); (ii) la ceguera voluntaria (que es calificada como conocimiento de segundo grado y se identifica con el estado mental de una persona que se abstiene deliberadamente de hacer averiguaciones para conocer); y (iii) el conocimiento constructivo (o conocimiento de tercer grado, que en realidad no es conocimiento, sino ausencia de conocimiento por negligencia) ${ }^{(100)}$. Según De Than y Heaton, la ceguera voluntaria es una forma de temeridad subjetiva (Cunningham recklessness), que contiene un elemento adicional que consiste en abstenerse deliberadamente de indagar a pesar de que los medios de conocimiento están disponibles ${ }^{(101)}$.

Un caso muy distinto es de la sospecha. Según Ormerod y Laird ${ }^{(102)}$, en los últimos tiempos, el Parlamento inglés ha demostrado mayor disposición para crear delitos con elementos subjetivos "de bajo nivel" como la sospecha. Ejemplos son las normas contra el blanqueo de capitales y contra el terrorismo. Las cortes inglesas no han sido ajenas a esta tendencia. En el caso Da Silva ${ }^{(103)}$, ni siquiera se exige que el estado mental de sospecha se sustente en motivos razonables. Por el contrario, se sostiene que la sospecha consiste en que el imputado haya pensado que existía una posibilidad, más que fantasiosa, de que el hecho relevante existía. Sin embargo, en el caso Saik ${ }^{(104)}$, a diferencia del anterior, la Cámara de los Lores considera que la sospecha sólo puede sustentarse en motivos razonables, de acuerdo a lo establecido en la Ley de Justicia Criminal de 1988.

\subsection{Supuestos de responsabilidad objetiva}

Como destaca Weigend, una particularidad de sistemas legales como el inglés es la existencia de una categoría de delitos que no exigen la prueba del estado mental e incluso, en algún caso, ni siquiera permiten una defensa de diligencia debida (due dilligence). Debe distinguirse dos supuestos.

2.3.1. Responsabilidad absoluta (absolute liability)

En los casos de responsabilidad absoluta, se atribuye responsabilidad penal al imputado a pesar de que este no ha realizado un acto u omisión voluntarios ni se ha verificado un estado mental en su conducta, restringiéndole la posibilidad de plantear defensas, salvo la de ser menor de diez años ${ }^{(105)}$. Ejemplo de estos casos lo constituyen los delitos de estado de cosas (state of affairs offences) (106). Un caso paradigmático es Larsonneur (1933), la imputada era una extranjera que recibió la orden de abandonar Reino Unido. Una vez en Eire, la policía la deportó y colocó en custodia de la policía de Reino Unido. Fue encontrada culpable, de acuerdo a la Ley de Extranjeros de 1920 (Aliens Order), de "ser un extranjero a quien se había rechazado la posibilidad de permanecer en territorio del Reino Unido, a pesar de lo cual se le encontró en Reino Unido"(107). Claramente no existió en la imputada un estado mental penalmente relevante. Es más, ni siquiera existió una conducta voluntaria, ya que su regreso a Reino Unido había sido forzado por la policía. Como bien señala Card, la responsabilidad absoluta "ofende cualquier idea de justicia"(108). Afortunadamente, como indica Padfield estos supuestos son hoy muy raros en Reino Unido, más aún cuando las cortes suelen admitir las defensas del imputado(109).

(100) Ormerod, Laird, Smith and Hogan's, 143-144.

(101) De Than, Heaton, Criminal Law, 80.

(102) Ormerod, Laird, Smith and Hogan's, 146.

(103) Da Silva [2006] EWCA Crim 1654.

(104) Saik [2006] UKHL 18, [2007] AC 18.

(105) Card, Card, Cross \& Jones Criminal Law, 129.

(106) Mcalhone, Wortley, Criminal Law, 74.

(107) Larsonneur [1933] 24 Cr App R 74. Al respecto, véase Martin, Key Facts Key Cases, 52. Véase también el caso Winzar v Chief Constable of Kent [1983] The Times, 28 Mar, DC.

(108) Card, Card, Cross \& Jones Criminal Law, 130 (traducción libre del autor).

(109) Padfield, Criminal Law, 63. 


\section{Armando Sánchez Málaga Carrillo}

\subsubsection{Responsabilidad estricta (strict liability)}

En los casos de responsabilidad estricta u objetiva, no se exige probar el estado mental o la negligencia del autor respecto de uno o algunos de los elementos objetivos del delito, aunque sí se requiere la probanza de estos últimos ${ }^{(110)}$. Se trata de delitos que abarcan sectores como la conducción de automóviles, el ambiente, la salud pública, la venta de comida y la comercialización de drogas ${ }^{(111)}$. Según Card, la responsabilidad estricta no infringe la presunción de inocencia establecida en la Convención Europea de Derechos Humanos, toda vez que lo que esta prohíbe es que la carga de la prueba de la ausencia de un estado mental se imponga al imputado(112). En esa línea, la Corte Europea de Derechos Humanos, en el caso Salabiaku vs. France ha establecido que "los Estados parte pueden, bajo ciertas condiciones, penalizar un hecho objetivo como tal, independientemente de que resulte de una intención delictiva o de negligencia"(113).

El número de casos de responsabilidad estricta en el derecho común es hoy muy reducido. Básicamente en el pasado existieron casos de alteración del orden público (public nuisance), ofensas contra la decencia pública (outraging public decency) y desacato (criminal contempt of court) ${ }^{(14)}$. Un ejemplo relativamente reciente es el caso Whitehouse vs. Gay News Ltd and Lemon, en el que los editores de Gay News publicaron un poema que describía actos homosexuales realizados con el cuerpo de Cristo luego de su muerte. Fueron condenados por blasfemia y la Cámara de los Lores rechazó su apelación, argumentando que el daño se había producido con la publicación, más allá de que los editores no hubieran tenido la intención de cometer blasfemia ${ }^{(115)}$.

En cambio, un gran número de los delitos establecidos en los estatutos son ofensas de responsabilidad estricta. Como explica Card, estas conductas son calificadas como criminales simplemente "porque se encuentran prohibidas" (mala prohibita)(116). Un ejemplo antiguo es el caso Prince, en el que el imputado fue condenado por sustraer de la posesión de sus padres a una mujer soltera menor de dieciséis años. A pesar de que la Corte aceptó que el imputado había dispuesto de elementos razonables para creer que la víctima era mayor de dieciséis años, la condena fue confirmada en atención a que, frente al elemento objetivo del delito consistente en la edad de la menor, operaba un supuesto de responsabilidad estricta ${ }^{(117)}$.

Con relación a las ofensas de responsabilidad estricta tipificadas en los estatutos, las cortes inglesas aplican hoy una "presunción de mens rea", que implica asumir que la voluntad del legislador, aun cuando no lo señale expresamente, es siempre exigir la concurrencia de elementos subjetivos en el delito, salvo que en el caso existan elementos para revertir dicha presunción ${ }^{(118)}$. Dicha presunción fue establecida en el caso Sweet vs. Parsley, en el que el imputado alquiló una casa de campo y la subarrendó a estudiantes, quienes consumieron cannabis en la misma. $A$ pesar de no conocer dicho hecho, el imputado fue condenado por estar involucrado en la administración de un predio utilizado con el propósito de fumar cannabis. La Cámara de los Lores anuló la condena y estableció que "cuando la ley es silenciosa en cuanto al

(110) Martin, Key Facts Key Cases, 47-48.

(111) Mcalhone, Wortley, Criminal Law, 77.

(112) CARD, Card, Cross \& Jones Criminal Law, 131.

(113) Salabiaku vs. France (1988) 13 EHRR 379, ECtHR, citado por Card, Card, Cross \& Jones Criminal Law, 131, quien también hace referencia al caso G v UK (2011) 53 EHRR SE25, ECtHR, en el que la Corte Europea de Derechos Humanos sostuvo que no era su competencia dictar el contenido del derecho penal interno.

(114) Card, Card, Cross \& Jones Criminal Law, 133.

(115) Whitehouse v Gay News Ltd and Lemon [1979], AC 617. Ver Padfield, Criminal Law, 63.

(116) Card, Card, Cross \& Jones Criminal Law, 134.

(117) Prince [1875], LR 2 CCR 154. Ver Padfield, Criminal Law, 63.

(118) Card, Card, Cross \& Jones Criminal Law, 135. 
estado mental, hay una presunción de que, con el fin de dar efecto a la voluntad del Parlamento, debemos leer la ley de forma que se exija el estado mental"(119).

La presunción fue ratificada en el caso Gammon (Hong Kong) Ltd vs. A-G of Hong Kong ${ }^{(120)}$, en el cual la Corte Civil (Privy Council) estableció los siguientes criterios: (1) existe una presunción de derecho de que las personas solo son culpables de una ofensa cuando han actuado con un determinado estado mental (mens rea); (2) la presunción es particularmente fuerte cuando la ofensa es de carácter "verdaderamente criminal"; (3) la presunción se aplica a ofensas establecidas en los estatuos y puede ser dejada sin efecto únicamente cuando así se desprende del estatuto; (4) la única situación en la que la presunción puede ser dejada sin efecto es cuando el estatuto se refiere a un asunto de interés social, como la seguridad pública; (5) aun cuando el estatuto se refiera a ese tipo de asuntos, la presunción se mantiene, salvo que pueda también ser demostrado que la creación de la ofensa de responsabilidad estricta será efectiva para promover los objetivos del estatuto y prevendrá la comisión del acto prohibido ${ }^{(121)}$.

La presunción -sobre todo para casos de verdadera connotación criminal- fue reforzada por la Cámara de los Lores años más tarde en el caso B (a minor) vs. DPP, en el que el imputado de quince años se sentó en un bus y pidió varias veces tener sexo oral a una menor de trece años, quien se negó. La defensa del imputado sostuvo que el menor había creído honestamente que la muchacha era mayor de catorce años. La Cámara de los Lores aceptó la apelación contra la condena y señaló que el caso Prince era "una reliquia de tiempos pasados y debía ser ignorado". Añadió que, si bien el Parlamento falló al no especificar el estado mental requerido por el delito, ello no implicaba necesariamente que la intención del Parlamento fuera que la responsabilidad sea estricta al extremo de que una honesta creencia en la edad del menor no pudiera constituir una defensa ${ }^{(122)}$. A pesar de este precedente, según Card, en los últimos años se han dado un significativo número de sentencias en las que se deja sin efecto la "presunción de mens rea"(123).

A efectos de determinar si la presunción rige o si se deja sin efecto, las cortes inglesas tienen en cuenta dos clases de factores. En primer lugar, valoran el contexto del estatuto $y$, especialmente, ciertas palabras contenidas en la regulación. Así, por ejemplo, los términos "permitir" (permitting), "sufrimiento" (suffering) y "voluntariamente" (wilfully) han sido interpretados en el sentido de que el delito exige la concurrencia de un estado mental, mientras que el término "causar" (cause) ha sido valorado en sentido contrario(124). Asimismo, se tiene en cuenta la redacción de otras ofensas en el estatuto. Por ejemplo, en el caso Cundy v Le Cocq, la Corte Superior (Queen's Bench Division) condenó al imputado por vender un licor intoxicante a una persona que se encontraba en estado de ebriedad, a pesar de que no sabía que se encontraba en dicho estado. Sin embargo, la Corte consideró que el elemento "a sabiendas" (knowingly) no se exigía en este caso como si estaba previsto para otras ofensas vinculadas y estableció que el desconocimiento podía ser únicamente un atenuante de pena ${ }^{(125)}$. En sentido contrario, en el caso Sherras v de Rutzen, la Corte Superior

(119) Sweet v Parsley [1969] 1 All ER 347. Ver Padfield, Criminal Law, 8a ed., 2012, p. 65 (traducción libre del autor).

(120) Gammon (Hong Kong) Ltd v Attorney-General of Hong Kong [1984] 2 All ER 503, (1984) 90 Cr App R 194. Véase Martin, Key Facts Key Cases, 48-49.

(121) Citado por Card, Card, Cross \& Jones Criminal Law, 140 (traducción libre del autor).

(122) B (a minor) vs. DPP (2000), citado por PADFIELD, Criminal Law, 64. Con relación a este caso, Ashworth, Horder, Principles of Criminal Law, 165, sostienen que elevó la presunción de mens rea a la categoría de "principio constitucional".

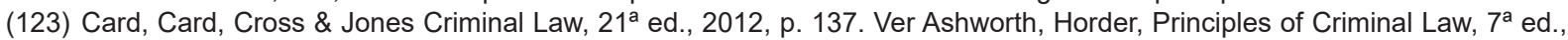
2013, p. 167. Destacan los casos Muhamad (2003) 2 WLR 1050 y Matudi (2003) EWCA Crim 697.

(124) Card, Card, Cross \& Jones Criminal Law, 141-144.

(125) Caso Cundy vs. Le Cocq (1884), citado por Padfield, Criminal Law, 63. 


\section{Armando Sánchez Málaga Carrillo}

(Divisional Court) anuló la condena contra el imputado que había vendido licor a un policía que estaba en servicio, ya que este había actuado con suficientes elementos para creer que el oficial se encontraba en descanso toda vez que no llevaba su brazalete de identificación ${ }^{(126)}$. En este caso, la Corte consideró que, a pesar de que el artículo del estatuto aplicable al caso no exigía expresamente el estado mental de conocimiento debía interpretarse que el conocimiento era exigible $^{(127)}$. En segundo lugar, frente a la falta de claridad del estatuto, las cortes inglesas valoran el contexto social. Así, tienen en cuenta la naturaleza del objeto de regulación (penal o administrativa), la gravedad de la ofensa y el daño ocasionado por la misma ${ }^{(128)}$. Sin embargo, la gravedad de la pena no es un elemento concluyente ${ }^{(129)}$.

Según Padfield, a favor de la responsabilidad estricta ${ }^{(130)}$ se plantean argumentos como la necesidad de proteger intereses colectivos; la necesidad de que los negocios sean administrados apropiadamente; la urgencia de que "las personas culpables" no escapen de la condena por falta de pruebas; la facilidad de sancionar este tipo de conductas; el efecto preventivo de la sanción; el incentivo que genera para la adopción de altos estándares de conducta; el ahorro de tiempo de las cortes como consecuencia de su aplicación; entre otros. En cambio, en contra de sancionar penalmente casos de responsabilidad estricta, se sostienen argumentos como que la responsabilidad no debe aplicarse a quien no es culpable; que es incorrecto sancionar a quienes han sido cuidadosos; que no hay evidencia de que este sistema de sanción eleve los estándares de conducta; que puede colocar a los pequeños negocios en un riesgo injusto; entre otros ${ }^{(131)}$. Finalmente, sostiene Card que la injusticia que involucra la existencia de responsabilidad estricta está siendo mitigada en los últimos tiempos a través de la previsión de varios tipos de defensas en los estatutos, destacando las de falta de negligencia (no negligence) y de diligencia debida (due diligence) $)^{(132)}$.

\subsection{Derecho procesal penal a partir del caso Woolmington v DPP (1935)}

La aproximación del derecho penal inglés a los elementos subjetivos del delito tiene una connotación aplicativa antes que conceptual. En esa medida, resulta importante tener en cuenta tres aspectos de orden estrictamente procesal: la carga de la prueba en el proceso penal inglés, la utilización de presunciones y los medios de prueba de los estados mentales que utilizan las cortes inglesas.

Con relación al primer punto, hasta hace algunas décadas, las cortes inglesas venían aplicando la Ley de la Corona de Foster (Foster's Crown Law), norma del año 1762 que sostenía que, en los casos de asesinato, una vez probado el hecho de matar, cualquier circunstancia eximente de responsabilidad (accidente, necesidad o enfermedad) debía ser probada por el imputado. Frente a dicha concepción, el caso Woolmington vs. DPP(133) marcó un hito, al establecer como principio del proceso penal la exigencia de que la acusación pruebe la culpabilidad del acusado más allá de una duda razonable. En este caso, el imputado era un trabajador agrícola de veintiún años que se había casado con una joven cuatro años

(126) Caso Sherras vs. de Rutzen (1895) 1 QB 918, citado por Padfield, Criminal Law, 64.

(127) Al respecto, ver Card, Card, Cross \& Jones Criminal Law, 145.

(128) Card, Card, Cross \& Jones Criminal Law, 146-149.

(129) Mcalhone, Wortley, Criminal Law, 78, para quienes el juez debe valorar, como mínimo, los siguientes factores: naturaleza del delito, gravedad del delito, redacción del tipo delictivo, redacción de otros artículos del estatuto, redacción de similares normas en otros estatutos, sentencias previas, existencia de una defensa, asuntos de interés público y efectivo preventivo.

(130) Véase más en Ashworth, Horder, Principles of Criminal Law, 161 y siguientes.

(131) Padfield, Criminal Law, 66-67.

(132) Card, Card, Cross \& Jones Criminal Law, 153. Con ello se busca evitar resultados como el del caso Callow v Tillstone [1900] 83 LT 411, D, en el que se condenó a un carnicero por vender carne inadecuada para el consumo humano, a pesar de que previamente había consultado a un veterinario quien le aseguró -falsamente- que el ganado estaba apto.

(133) Woolmington Appellant vs. DPP [1935] AC 462. 
menor, quien, a los pocos meses de la boda, lo abandonó y se fue a vivir con su madre, la señora Smith, quien residía al lado de su hermana, la señora Brine. Esta última, en la mañana del 10 de diciembre de 1934, se encontraba en el patio trasero de su vivienda y escuchó la voz del imputado diciendo: "¿Vuelves o no?" y "¿Dónde está tu madre?" Entonces escuchó cerrarse de golpe la puerta trasera de la casa vecina y el sonido de un disparo. Miró por la ventana y vio al imputado irse, a quien llamó, pero no le respondió. La señora Brine entró a la casa contigua y encontró a su sobrina tumbada en el tapete. Le habían disparado al corazón. Un jurado condenó al imputado a la pena de cadena perpetua por el delito de homicidio intencional. Sin embargo, la Cámara de los Lores anuló la decisión al considerar que se trataba de un caso de homicidio involuntario, en base a los siguientes argumentos:

- Se había efectuado una indebida interpretación de la Ley de la Corona de Foster, la cual no establecía una presunción de la intención, sino que indicaba que, cuando se demuestra que el acto consciente del imputado ha matado a un hombre y nada más aparece en el caso, hay evidencia sobre la cual el jurado puede -no debeencontrarlo culpable de asesinato.

- Mientras que la acusación debe probar la culpabilidad del imputado, no existe tal carga en el imputado para probar su inocencia.

- Si existe una duda razonable, creada por las pruebas presentadas por la fiscalía o por el imputado, ello significa que la fiscalía no ha podido probar su caso y que el imputado tiene derecho a ser absuelto.

Siguiendo a Card, esta sentencia no sólo establece la regla general de que la acusación debe probar los hechos en los que funda su acusación y la culpabilidad del acusado más allá de la duda razonable, sino que debe además negar todas las defensas que presente el imputado(134). Sin embargo, con posterioridad, en casos como Sheldrake vs. DPP, la Cámara de los Lores ha sostenido que está justificado imponer una carga legal de prueba al imputado en determinados casos, en los que este está en mejores condiciones que la acusación para acreditar un hecho(135).

Con relación al segundo punto, en el proceso penal inglés se rechazan en principio las presunciones de derecho que atribuyan responsabilidad penal al imputado. Sin embargo, se admiten presunciones de derecho que eximan de responsabilidad, como es el caso de presumir incapaces de cometer una ofensa a los niños menores de diez años. Distinto es el caso de las denominadas presunciones de hecho, que son más bien reglas de evidencia y forman parte medular del proceso penal inglés. Al respecto, Card ${ }^{(136)}$ sostiene que existe una presunción de hecho cuando, a partir de la prueba de un hecho, el jurado puede inferir la existencia de otro hecho, que en estricto no puede probar. Se trata de un proceso de inferencia, que suele ser el único medio para probar el estado mental del imputado.

Finalmente, con relación al tercer punto, Card ${ }^{(137)}$ sostiene que, a efectos de probar el estado mental del imputado, las cortes inglesas suelen valorar los siguientes medios de prueba: (i) las declaraciones del imputado (incluso aquellas vertidas fuera de juicio); (ii) la presencia o ausencia de motivos en el imputado (aunque estos suelen tener un rol residual en la decisión definitiva del caso(138); (iii) la situación y conducta del imputado; y

(134) Card, Card, Cross \& Jones Criminal Law, 111-112.

(135) Sheldrake v DPP [2004] UKHL 43. Véase Martin, Key Facts Key Cases, 16-17. Véase también Card, Card, Cross \& Jones Criminal Law, 112-113, quien hace referencia a aquellos casos en los que el imputado tiene la carga de probar las defensas o aquellos supuestos en los que el estatuto establece una presunción de derecho contra el imputado.

(136) Card, Card, Cross \& Jones Criminal Law, 115-116.

(137) Cónfer. Card, Card, Cross \& Jones Criminal Law, 116-117.

(138) Oxman, Sistemas de imputación subjetiva en Derecho Penal, 67. En igual sentido, Mcalhone, Wortley, Criminal Law, 51. 


\section{Armando Sánchez Málaga Carrillo}

(iv) las consecuencias naturales y probables de los actos del imputado. Destacan por su importancia los dos últimos.

Respecto de la situación y conducta del imputado, Card explica que "la prueba de que el imputado realizó los elementos objetivos del delito puede justificar una inferencia de que lo hizo voluntariamente, con conocimiento de las circunstancias circundantes y, cuando proceda, con intención o previsión en cuanto a sus consecuencias normales, aunque nunca debe olvidarse que esta es sólo una inferencia y el jurado puede concluir que no está justificada en los hechos particulares del caso. Si se ofrece una explicación creíble, el jurado debe, por supuesto, considerar la prueba en su totalidad y, si tiene alguna duda razonable, la regla general de que la acusación tiene la carga de la prueba obliga a favorecer al imputado con la duda. Si el imputado, en cambio, no ofrece una explicación creíble, normalmente se deducirá la inferencia"(139). Finalmente, con relación a la valoración de las consecuencias naturales y probables de los actos del imputado, el mismo Card sostiene que ciertos actos son susceptibles de producir consecuencias particulares. Este hecho, junto con el hecho de que la gente suele prever las consecuencias normales de su conducta, ha llevado a hacer referencia a una presunción de que todos pretenden o prevén las consecuencias naturales y probables de sus actos conscientes. Card entiende que dicha afirmación es inofensiva siempre que se recuerde que la presunción es una de hecho y no se exija al imputado, como cuestión de derecho, aportar pruebas que demuestren que no pretendió o que no previó las consecuencias naturales y probables de ese acto $^{(140)}$

\section{Conclusiones}

Como señala Chiesa, "se puede aprender mucho a partir de comprender cómo los sistemas legales extranjeros han abordado cuestiones importantes de la teoría criminal"(141). Ese ha sido el propósito de este artículo. Si bien los resultados evidencian que la discusión en Reino Unido acerca de los elementos subjetivos se encuentra aun en estado incipiente, el derecho penal inglés proporciona una perspectiva interesante y distinta de análisis. Esta consiste en anteponer el nivel aplicativo de la problemática del dolo al nivel conceptual, que sólo será satisfactorio abordarlo si es que permite o hace viable su aplicación en el proceso penal. Más allá de ello, debe rescatarse como aportes del derecho penal inglés en esta materia la distinción entre motivos y estados mentales; el postulado de un concepto procesal de dolo recogido a través de la figura de la intención oblicua, que más allá de su confuso nombre muestra capacidad de rendimiento; y el desarrollo de criterios de inferencia de los elementos subjetivos del delito. Cabe resumir los cinco criterios específicos de inferencia de la intención, que son de alguna manera postulados procesales de prueba del dolo en el caso concreto:

- Un primer grupo de criterios jurisprudenciales sostienen que, para imputar la comisión de un delito doloso (intencional), no es necesario acreditar que el imputado haya actuado con la intención de producir el resultado típico. Basta con la existencia de "intención oblicua". La intención oblicua no es una estructura conceptual ni una forma de intención, sino un medio de inferencia de la intención, es decir, un instrumento de aplicación del concepto.

- Un criterio específico de inferencia de la intención oblicua es el "baremo objetivo" establecido en el caso DPP vs. Smith (1961). Según este, existe homicidio intencional cuando la muerte del sujeto pasivo era previsible según la perspectiva de una persona razonable situada en la posición del autor. Se trata de un proceso

(139) Card, Card, Cross \& Jones Criminal Law, 116.

(140) Card, Card, Cross \& Jones Criminal Law, 117.

(141) Chiesa, "Comparative Criminal Law", en Hörnle, The Oxford Handbook of Criminal Law, 1113 (traducción libre del autor). 
Sistema penal inglés e imputación subjetiva English criminal system and mental states inference rules de atribución objetiva del estado mental, similar a los enfoques normativos más radicales del Derecho penal continental.

- Un segundo criterio específico de inferencia de la intención oblicua es el de la "consecuencia prácticamente segura" establecido en el caso Hyam vs. DPP (1975). Según este criterio, el resultado de un delito de homicidio es intencional, aun cuando no hubiera sido el propósito del autor causarlo, si es que el autor tuvo conocimiento de que el resultado era una consecuencia prácticamente segura de su conducta. Se trata de un enfoque que guarda similitud con la teoría de la probabilidad subjetiva del Derecho penal continental.

- Un tercer criterio específico de inferencia de la intención oblicua es el criterio de la "consecuencia natural o certeza moral" planteado en el caso Regina vs. Moloney (1985). De acuerdo a este criterio, sólo puede afirmarse que el imputado actuó intencionalmente si es que él mismo tuvo conocimiento que el resultado típico era una consecuencia natural de su conducta. Se trata también de la aplicación de un baremo subjetivo de probabilidad, aunque con un contenido presuntivo que ha generado más de una duda.

- Un cuarto criterio específico de inferencia de la intención oblicua es el criterio de la "alta probabilidad" del caso Regina vs. Hancock \& Shankland (1986). De acuerdo a este, cuanto más alta es la probabilidad de una consecuencia, es más probable que esta haya sido prevista $y$, si la consecuencia ha sido prevista, es más alta la probabilidad de que la consecuencia haya sido intencional.

- Un quinto criterio específico de inferencia de la intención oblicua es el criterio de la "virtual certeza" del caso Regina v Nedrick (1986), ratificado parcialmente en el caso Regina vs. Woollin (1998) y en Regina v MD (2004). Según este criterio, la previsión del resultado no es más que una prueba de la cual se puede inferir la intención del imputado que ha apreciado la virtual certeza del resultado generado por su conducta.

Más allá de la pertinencia de cada criterio específico de inferencia de la intención oblicua, que responde a momentos distintos de la evolución jurisprudencial, todos se enmarcan en el nivel de análisis aplicativo antes que en el conceptual.
Lo importante para la tradición jurídica inglesa no es establecer la definición de la intención, sino más bien dictar los criterios que describen un caso modelo o un caso tipo a partir del cual se puede -no se debe- atribuir un determinado estado mental, según las circunstancias del caso. Como también se ha visto a lo largo del presente artículo, otro grupo de criterios jurisprudenciales se elaboran en torno a la figura de la temeridad, que, en su acepción subjetiva, se asemeja a los casos de dolo eventual del Derecho penal continental. Se trata de aquellos casos en los que el imputado decide llevar a cabo riesgos injustificables que pueden dañar a terceros. En este supuesto, las cortes inglesas han seguido los criterios de inferencia establecidos en el caso Regina vs. Cunningham (1957) y ratificados (tras un breve receso en el que se defendió una versión objetiva de la temeridad) por el caso Regina vs. G (2003). Según esta línea jurisprudencia, la temeridad subjetiva se infiere a partir de elementos que indiquen que el imputado tuvo conocimiento de que su conducta podía causar un grave daño (indicio de reconocimiento de la existencia del riesgo) y, a pesar de ello, insistió con realizarla (indicio de toma deliberada del riesgo). Como ha podido observarse, se trata de criterios de inferencia que toman en cuenta el contexto del caso.

Finalmente, cabe destacar alguna diferencia entre el modo en que el derecho anglosajón y el derecho continental abordan el problema en cuestión. Antes de ello, no puede ocultarse que la discusión acerca del método de aproximación a los estados mentales en la jurisprudencia inglesa se asemeja a la mantenida en el Derecho penal occidental entre los enfoques psicológicos y los enfoques normativos del dolo. En Reino Unido esta discusión se traduce en el conflicto entre el principio de autonomía individual y el principio de bienestar, existiendo dos planteamientos muy diferenciados acerca de lo que debe ser acreditado en juicio. Por un lado, el 


\section{Armando Sánchez Málaga Carrillo}

planteamiento de los subjetivistas, quienes proponen que, al menos en los delitos más graves, el elemento mental requiere la prueba de que el imputado tuvo conciencia personal de sus acciones y fue consciente de las circunstancias relevantes y de las consecuencias que forman parte de los elementos objetivos del delito. Por otro lado, el planteamiento de los objetivistas, para quienes es suficiente probar que una persona razonable hubiera sido consciente de las circunstancias y consecuencias relevantes que forman parte del delito, independientemente de si el imputado fue consciente de las mismas. Existen, asimismo, múltiples propuestas intermedias, que se alinean con el proceso continental de normativización del dolo.

Lo cierto es que, más allá del enfoque que se adopte, el desarrollo reciente de la jurisprudencia penal inglesa ha estado marcado por lo menos por tres factores. En primer lugar, en Reino Unido se reconoce mayoritariamente que los jueces penales o los jurados populares no tienen a su disposición una prueba directa del estado mental del imputado. En segundo lugar, existe una tendencia de la jurisprudencia penal inglesa a apartarse de las presunciones de Derecho, como aquella que antiguamente establecía que el imputado necesariamente prevé y tiene la intención de realizar las consecuencias naturales de su conducta. Se asume así una teoría racional de la intención, como la planteada por Williams ${ }^{(142)}$. En tercer lugar, las cortes inglesas muestran una tendencia a apartarse de criterios o valoraciones morales a la hora de determinar el estado mental imputado, como ocurrió en el caso Regina vs Moloney (1985), aunque no puede negarse que existen propuestas, como la de Husak ${ }^{(143)}$, que abogan por la valoración de los motivos del agente. Este desarrollo ha llevado a las cortes inglesas a reconocer la necesidad de recurrir a la inferencia como herramienta para establecer los estados mentales del imputado. Así, a partir de la acreditación de la acción realizada y del contexto en el que tuvo lugar -incluyendo la conducta previa y la ejecución-, las cortes inglesas establecen reglas para inferir el estado mental con el que el sujeto activo obró. Según un criterio ampliamente establecido, la presunción de inocencia se quiebra cuando el juez o el jurado son persuadidos de que un estado mental se evidencia más allá de toda duda razonable. Aunque con una terminología quizás distinta, puedo afirmar entonces que, en las últimas décadas, el problema central para la jurisprudencia penal inglesa reside en cómo formular la imputación -o cómo plantear criterios de inferencia- en los casos de dolo no intencional (dolo de segundo grado o casos de intención oblicua y dolo eventual o casos de temeridad subjetiva).

Quizás la diferencia más evidente entre ambos sistemas es la que se refiere a la incorporación de formas de responsabilidad objetiva en el derecho penal inglés. Sin embargo, la existencia de delitos de responsabilidad estricta, más allá de la discusión sobre su legitimidad, ha permitido que las cortes inglesas se planteen la necesidad de asumir una perspectiva crítica y formulen pautas interpretativas que protejan el principio de mens rea o, en términos del derecho penal occidental, el principio de culpabilidad ${ }^{(144)}$. En esa medida, el tratamiento de la responsabilidad objetiva en el Derecho penal inglés constituye el espejo de lo que podría ocurrir si se lleva a cabo en el derecho penal continental el proyecto de objetivación del dolo hasta sus últimas consecuencias.

\section{Referencias bibliográficas}

Ashworth, Andrew y Horder, Jeremy. 2013. Principles of Criminal Law. $7^{\text {a }}$ ed. Oxford University Press.

Bouvier, Hernán (director). 2013. Discusiones XIII. Ignorancia deliberada y Derecho penal. Buenos Aires: EdiUNS.

(142) Glanville Williams, Criminal Law. The General Part, 2a ed. (Londres: Steven \& Sons Limited, 1961); el mismo autor, The mental element in Crime (Jerusalem: Magnes Press, The Hebrew University, 1965).

(143) Douglas Husak, "Motive and Criminal Liability”, en Criminal Justice Ethics (enero 1989), 3-14.

(144) Con relación a la aplicación del principio de culpabilidad en el marco del constitucionalismo penal, véase Franco Bricola, Teoría General del Delito (Buenos Aires: B de F, 2012). 
Sistema penal inglés e imputación subjetiva English criminal system and mental states inference rules
Bricola, Franco. 2012. Teoría General del Delito. Buenos Aires: $\mathrm{B}$ de $\mathrm{F}$.

Card, Richard. 2012. Card, Cross \& Jones Criminal Law. 21 ${ }^{\text {a }}$ ed. Oxford: Oxford University Press.

Chiesa, Luis. 2014. Comparative Criminal Law. En The Oxford Handbook of Criminal Law, 1089 y siguientes. Oxford: Oxford University Press.

Corcoy, Mirentxu. 2008. El delito imprudente. Criterios de imputación del resultado. $2^{\mathrm{a}}$ ed. Buenos Aires: B de F.

De Than, Claire y Heaton, Russell. 2013. Criminal Law. $4^{\mathrm{a}}$ ed. Oxford: Oxford University Press.

Hruschka, Joachim. 2009. Sobre la difícil prueba del dolo. En Imputación y Derecho penal. Estudios sobre la teoría de la imputación. 181 y siguientes. Pamplona: B de F.

Husak, Douglas. 1989. "Motive and Criminal Liability". En Criminal Justice Ethics 8 (Enero): 3-14. https://doi. org/10.1080/0731129x.1988.9991846

Laurenzo, Patricia. 1999. Dolo y conocimiento. Valencia: Tirant lo Blanch

Martin, Jacqueline. 2014. Key Facts Key Cases. Criminal Law. Nueva York: Routledge Taylor \& Francis Group.

Mcalhone, Christina y Wortley, Natalie. 2013. Criminal Law. The Fundamentals. $3^{\text {a }}$ ed. Sweet $\&$ Maxwell.

Mir Puig, Santiago. 2015. Derecho penal, Parte General. 10ª ed. Barcelona: Reppertor.

Ormerod, David y Laird, Karl. 2015. Smith and Hogan's Criminal Law. 14ª ed. Oxford: Oxford University Press.

Oxman, Nicolás. 2016. Sistemas de imputación subjetiva en Derecho Penal. El modelo angloamericano. México: Tirant lo Blanch.

Padfield, Nicola. 2012. Criminal Law. $8^{a}$ ed. Oxford: Oxford University Press.
Pérez, Gabriel. 2010. El dolo eventual. Hacia el abandono de la idea de dolo como estado mental. Buenos Aires: Hammurabi.

Ragués, Ramon. 1999. El dolo y su prueba en el proceso penal. Barcelona: Bosch.

Ragués, Ramon. 2008. La ignorancia deliberada en Derecho penal. Barcelona: Atelier.

Sánchez-Málaga, Armando. 2018. Una teoría para la determinación del dolo. Premisas teóricas e indicadores prácticos. Montevideo: $\mathrm{B}$ de $\mathrm{F}$.

Weigend, Thomas. 2014. "Subjective elements of criminal liability". En The Oxford Handbook of Criminal Law. 490 y siguientes. Oxford: Oxford University Press.

Williams, Glanville. 1961. Criminal Law. The General Part. 2a ed. Londres: Steven \& Sons Limited.

Williams, Glanville. 1965. The mental element in Crime. Jerusalem: Magnes Press, The Hebrew University.

\section{Jurisprudencia}

Prince [1875], LR 2 CCR 154

Cundy vs. Le Cocq [1884]

Latimer [1886] 17 QBD 359

Sherras vs. de Rutzen [1895]

Callow vs. Tillstone [1900] 83 LT 411, D

Larsonneur [1933] 24 Cr App R 74

Woolmington Appellant vs. DPP [1935] AC 462

Steane [1947] KB 997, [1947] 1 All ER 813 


\section{Armando Sánchez Málaga Carrillo}

Cunningham [1957] 2 All ER 412, [1957] 41

Cr App R 155

DPP vs. Smith [1960] AC 290

Sweet vs. Parsley [1969] 1 All ER 347

Mohan [1975] 2 All ER 193, [1975] 60 Cr App R 272

Hyam vs. DPP [1975] AC 55

DPP vs. Majewski [1977] AC 443

Whitehouse vs. Gay News Ltd and Lemon [1979], AC 617

Caldwell vs. MPC [1982] AC 341, [1981] All ER 961

Winzar vs. Chief Constable of Kent [1983] The Times, 28 Mar, DC

Gammon (Hong Kong) Ltd vs. AttorneyGeneral of Hong Kong [1984] 2 All ER 503, (1984) 90 Cr App R 194

Moloney [1985] 1 All ER 1025, [1985] $81 \mathrm{Cr}$ App R 93

Hall [1985] $81 \mathrm{Cr}$ App R 260 at 264, [1985] Crim LR 377
Hancock and Shankland [1986] 1 All ER 641, [1986] 82 Cr App R 264

Nedrick [1986] 3 All ER 1, [1986] 83 Cr App R 267

Salabiaku vs. France (1988) 13 EHRR 379, ECtHR

Woollin [1998] UKHL 28, [1999] 1 Cr App R 8

B (a minor) vs. DPP [2000]

G [2003] UKHL 50, [2004] 1 AC 1034, [2003] 4 All ER 765

Muhamad [2003] 2 WLR 1050

Matudi [2003] EWCA Crim 697

MD [2004] EWCA Crim 1391

Sheldrake vs. DPP [2004] UKHL 43

Goldstein and Rimmington [2005] UKHL 63

Jones et al [2006] UKHL 16

Da Silva [2006] EWCA Crim 1654.

Saik [2006] UKHL 18, [2007] AC 18.

Chambers [2008] EWCA Crim 2467

G vs. UK [2011] 53 EHRR SE25, ECtHR 